\title{
Minimally invasive biomarker confirms glial activation present in Alzheimer's disease: a preliminary study
}

This article was published in the following Dove Press journal:

Neuropsychiatric Disease and Treatment

23 August 201I

Number of times this article has been viewed

\section{Napapon Sailasuta \\ Kent Harris \\ Thao Tran \\ Brian Ross}

Clinical MR Unit, Huntington Medical Research Institutes, Pasadena, CA, USA
Correspondence: Napapon Sailasuta Clinical MR Spectroscopy Unit, I0 Pico Street, Pasadena, CA 9II05, USA Email pom4pom@gmail.com
Abstract: We applied ${ }^{13} \mathrm{C}$ magnetic resonance spectroscopy (MRS), a nonradioactive, noninvasive brain imaging technique, to quantify the oxidation of $\left[1-{ }^{13} \mathrm{C}\right]$ acetate in a conventional clinical magnetic resonance imaging (MRI) scanner in five consecutive elderly subjects at various clinical stages of Alzheimer's disease (AD) progression. $\left[1{ }^{13} \mathrm{C}\right]$ acetate entered the brain and was metabolized to $\left[5-{ }^{13} \mathrm{C}\right]$ glutamate and glutamine, as well as $\left[1-{ }^{13} \mathrm{C}\right]$ glutamate and glutamine, and the final glial oxidation product, ${ }^{13} \mathrm{C}$ bicarbonate, at a linear rate. Calculation of the initial slope was similar in a single subject, examined twice, 1 month apart (test-re-test $8 \%$ ). Mean rate of cerebral bicarbonate production in this elderly group was $0.040 \pm 0.01(n=5)$. Assuming that the rate of conversion of acetate to bicarbonate is a reflection of glial metabolic rate and that glial metabolic rate is a surrogate marker for 'neuroinflammation', our preliminary results suggest that $\left[1-{ }^{13} \mathrm{C}\right]$ MRS may provide biomarkers for diseases, believed to involve microglia and other cells of the astrocyte series. Among these is AD, for which novel drugs which ameliorate the damaging effects of neuroinflammation before symptoms of dementia appear, are in advanced development. The value of ${ }^{13} \mathrm{C}$ MRS as an early, noninvasive biomarker may lie in the conduct of cost-effective clinical trials.

Keywords: Alzheimer's disease, noninvasive biomarker, glial activation

\section{Introduction}

In Alzheimer's disease (AD), incidence and prevalence increase with age. $A D$ is the sixth leading cause of death in the US, and there are no effective therapies for the disease. Development of disease-modifying treatments for $\mathrm{AD}$ has been both expensive and unsuccessful to date. A shortcoming of current largely neuronal biomarkers, magnetic resonance imaging (MRI), amyloid imaging, and cerebrospinal fluid biomarkers, is the absence of an accepted biomarker for glial activation. ${ }^{1,2}$ Neuroinflammation, also termed glial activation, has long been implicated in the pathology of $\mathrm{AD} .^{3}$ Recent research has shown that there are early pathological changes in the brains of persons with predementia memory decline, which can even be detected in asymptomatic individuals who may eventually develop $\mathrm{AD}^{4,5}$ This phenomenon occurs early in the course of $\mathrm{AD}$ possibly before the more extensive neuron damage monitored by clinical tests. Most AD clinical trials depend on measures of rates of change in highly variable and insensitive clinical and cognitive measures. Therefore, there is an urgent need for appropriate biomarkers that can serve as outcome endpoints to detect progression of disease.

Magnetic resonance spectroscopy (MRS) is a powerful method for measuring brain metabolism. Noninvasive proton MRS has been used to measure brain chemical contents 
statically ${ }^{6-8}$ while minimally invasive carbon MRS has been used to measure brain metabolic processes in action, dynamically. ${ }^{9}$ With appropriate infusion of brain exogenous labeled substrates, neuronal and glial metabolic rates have been reported in numerous neurodegenerative diseases. ${ }^{10-14}$ It is accepted that acetate, which enters the brain tricarboxylic acid cycle via an astrocyte-specific enzyme, can be used as a tracer for astrocyte or glial oxidative metabolism. ${ }^{15-17}$ Both $\mathrm{C} 1$ and $\mathrm{C} 2$ labeled acetate have been used successfully to study glial metabolism in intact human brains. ${ }^{10,13,14}$ In aging, evidence of upregulation of astrocytes (glia) metabolism was demonstrated with an increase of $25 \%$ in older subjects compared with younger adults using labeled $\mathrm{C} 2$ acetate as exogenous substrate. ${ }^{18}$

In this preliminary communication, we employed a short protocol developed previously ${ }^{19}$ to directly measure glial dysfunction in Alzheimer's patients using $\mathrm{C} 1$ acetate as an exogenous labeled substrate.

\section{Methods}

\section{Patients}

The studies were approved by the local internal review board (Huntington Memorial Hospital), and all patients gave written informed consent. A total of $24 \mathrm{MRI} / \mathrm{MRS}$ studies were performed on six subjects of whom two had
AD, two had mild cognitive impairment (MCI) and two were healthy older adults with mean age of $78 \pm 3$ years, and two were females.

\section{Neuropsychological assessments}

All subjects underwent extensive neuropsychological evaluation using the standard test battery to evaluate AD. ${ }^{20}$ Briefly: premorbid estimates of intellectual functioning were performed (Wechsler Test of Adult Reading). The core neuropsychological battery included the Wechsler Adult Intelligence Scales, third ed. (WAIS-III) and the Wechsler Memory Scales, third ed. (WMS-III) Domains of Attention/Concentration/Working Memory (WAIS-III Digit Span, Letter-Number Sequencing and Arithmetic), Psychomotor/Information processing (WAIS-III Symbol Search and Digit Symbol, Stroop word reading and color naming), Language functions (COWAT-FAS and Animals, WAIS-III Information), Verbal Memory (WMS-III Logical Memory I and II, California Verbal Learning Test-II), Nonverbal Memory (Brief Visual Memory Test-Revised, Rey Osterreich Complex Figure Test-Delay), Visuospatial/ construction (WAIS-III Block Design, Picture Completion, Ruff Figural Fluency, Judgment of Line Orientation, Rey Osterreich Complex Figure Test-Copy) Executive Functions

Table I Compilations of subjects' characteristics, proton, carbon MRS, and neuropsychological assessment results

\begin{tabular}{|c|c|c|c|c|c|c|}
\hline & $\begin{array}{l}\text { Patient I } \\
\text { Control }\end{array}$ & $\begin{array}{l}\text { Patient } 2 \\
\text { Control }\end{array}$ & $\begin{array}{l}\text { Patient } 3 \\
\mathrm{MCl}\end{array}$ & $\begin{array}{l}\text { Patient } 4 \\
\text { MCl }\end{array}$ & $\begin{array}{l}\text { Patient } 5 \\
\text { AD }\end{array}$ & $\begin{array}{l}\text { Patient } 6 \\
\text { AD }\end{array}$ \\
\hline \multicolumn{7}{|l|}{ Subject characteristics } \\
\hline Age & 80 & 83 & 77 & 81 & 76 & 76 \\
\hline Gender & M & M & M & M & $\mathrm{F}$ & $\mathrm{F}$ \\
\hline MMSE & 30 & 28 & 26 & 27 & 22 & 22 \\
\hline \multicolumn{7}{|l|}{ Proton MRS results } \\
\hline $\mathrm{NAA} / \mathrm{Cr}$ & 1.45 & 1.37 & 1.47 & 1.37 & 1.62 & 1.39 \\
\hline $\mathrm{ml} / \mathrm{Cr}$ & 0.56 & 0.72 & 0.77 & 0.74 & 0.85 & 0.83 \\
\hline $\mathrm{NAA} / \mathrm{ml}$ & 2.6 & 1.92 & 1.92 & 1.85 & 1.34 & 1.67 \\
\hline \multicolumn{7}{|l|}{ Carbon MRS results } \\
\hline $\begin{array}{l}\text { Rate of bicarbonate } \\
\text { production (\%FE/minute) }\end{array}$ & 0.023 & 0.03 & 0.042 & 0.033 & 0.056 & 0.06 \\
\hline \multicolumn{7}{|c|}{ Neuropsychological assessment (Z scores) } \\
\hline $\begin{array}{l}\text { Attention/concentration } \\
\text { Working memory }\end{array}$ & WNL & WNL & -2 & WNL & -1.6 & -1.6 \\
\hline \multicolumn{6}{|l|}{ Information processing } & -1.5 \\
\hline Language functions & WNL & WNL & -1.5 & WNL & -1.5 & -1.5 \\
\hline Verbal memory & WNL & WNL & -1.3 & -1.3 & -3 & -3 \\
\hline Nonverbal memory & WNL & WNL & -3 & WNL & -3 & -3 \\
\hline $\begin{array}{l}\text { Visuospatial/ } \\
\text { construction }\end{array}$ & WNL & -1.4 & -1.4 & -2 & -2 & -2 \\
\hline Executive functions & WNL & -1.4 & -2.5 & WN: & -3 & -3 \\
\hline Motor functions & WNL & WNL & -1.3 & WNL & WNL & WNL \\
\hline
\end{tabular}

Abbreviations: $\mathrm{AD}$, Alzheimer's disease; $\mathrm{Cr}$, creatine; $\mathrm{FE}$, fractional enrichment; ml, myo-inositol; $\mathrm{MCl}$, mild cognitive impairment; $\mathrm{MMSE}$, mini-mental state examination; MRS, magnetic resonance spectroscopy; NAA, N-acetyl aspartate; WNL, within normal range. 


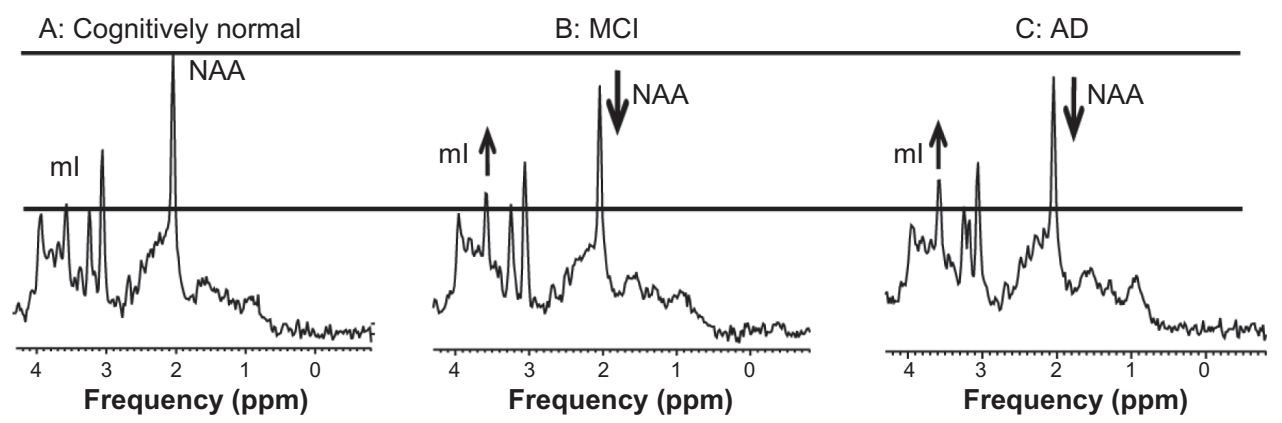

Figure I Proton MRS spectra from healthy elderly (A), an elderly subject with $\mathrm{MCl}(\mathbf{B})$ and an $A D$ patient $(\mathbf{C})$. Spectra were scaled to creatine peak intensity. Abbreviations: AD, Alzheimer's disease; $\mathrm{MCl}$, mild cognitive impairment; ml, myo-inositol; MRS, magnetic resonance spectroscopy; NAA, N-acetyl aspartate.

(Delis-Kaplan Executive Functions System - Tower Test), and Motor Functioning (Purdue Pegboard) were assessed.

All subjects underwent mini-mental state examination (MMSE). Criteria for MCI cut-off from normal included absence of dementia (MMSE $\geq 23$ ) essentially preserved activities of daily living, the presence of cognitive and/or memory complaints, and impairment $>1$ standard deviation below age norms on one or more immediate or delayed memory tests or $\geq 2$ nonmemory tests. ${ }^{21}$ Criteria for AD classification included MMSE score $<23$, impairment in activities of daily living, and $\geq 2$ standard deviations below age norms on a majority of memory tests.

\section{Neuroimaging and spectroscopy}

Examinations were performed on a GE 1.5 T MRI scanner equipped with non-proton MRS capability as previously prescribed. ${ }^{22}$ Localized MRI was acquired with a 30 -slice T2-weighted fast spin echo imaging sequence with echo time $(\mathrm{TE})=96$ milliseconds, repetition time $(\mathrm{TR})=4$ seconds, slice thickness $=5 \mathrm{~mm}, 1$ excitation, and $256 \times 192$ data acquisition matrix using a single channel quadrature head coil for both transmitting and receiving. These localizer images were used to prescribe two single voxel proton MRS acquisitions of posterior cingulate grey matter and white matter (PROBE-p $\mathrm{TE}=35$ milliseconds, $\mathrm{TR}=1.5$ seconds, $8 \mathrm{~mL}$ voxel, 128

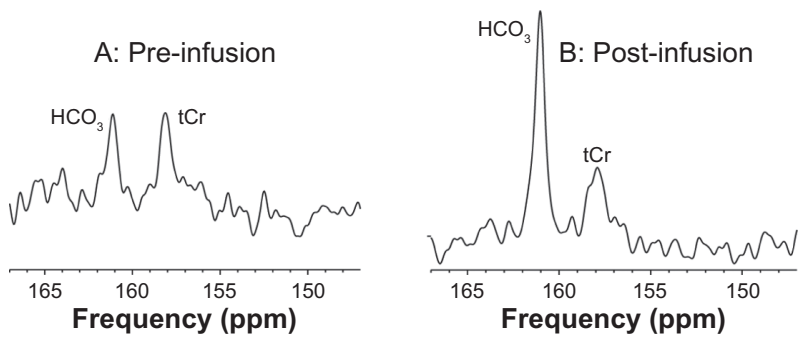

Figure 2 Typical spectra (147-167 ppm region) of ${ }^{13} \mathrm{C}$ MRS in an AD subject at baseline (A) and at I hour after start of infusion (B).

Abbreviations: MRS, magnetic resonance spectroscopy; AD, Alzheimer's disease; $\mathrm{tCr}$, total creatine. averages). For proton decoupled ${ }^{13} \mathrm{C} \mathrm{MRS}$, scanning protocol is similar to that previously described. ${ }^{19,23}$ Briefly, prior to the start of the infusion protocol, a natural abundance ${ }^{13} \mathrm{C} \mathrm{MRS}$ was acquired for 30 minutes of five blocks pulse, to acquire data averaging a Waltz-4 bi-level proton decoupling and nuclear OverHouser (NOE) scheme with a power level of $5 \mathrm{~W}$ during decoupling and $0.9 \mathrm{~W}$ during the NOE period. Subsequently, intravenous administration of stable isotope enriched $1-{ }^{13} \mathrm{C}$ acetate (Cambridge Isotopes Laboratories, Andover, MA; FDA IND 59,950) was performed with the subjects lying comfortably outside the MRI scanner for 60 minutes. The patients were then swiftly positioned back in the MRI scanner and data acquisition was performed for another 60 minutes.

\section{Data and statistical analysis}

Automated spectral processing for single voxel proton MRS data was performed using the commercially available LCModel software ${ }^{24}$ using a standard $1.5 \mathrm{~T}$ reference basis set for semi-quantification. The results are reported as metabolic ratios.

For ${ }^{13} \mathrm{C}$ MRS time series data were processed as previously described using an observer-independent automatic IDL-based software developed in house and SAGE (GE Healthcare, Milwaukee, WI). ${ }^{14}$ The rate of bicarbonate production was determined using the difference between the amount of measured bicarbonate level pre- and postinfusion over the time from the start of infusion to the end of data acquisition. ${ }^{19}$

Simple statistical analysis was performed using linear regression, and the goodness of linear fit is reported as $R^{2}$.

\section{Results}

Subject characteristics, MRS, and neuropsychological evaluation results are shown in Table 1.

Proton MRS shows increased myoinositol to creatine ratio and decreased $\mathrm{N}$-acetyl aspartate to myoinositol ratio, 

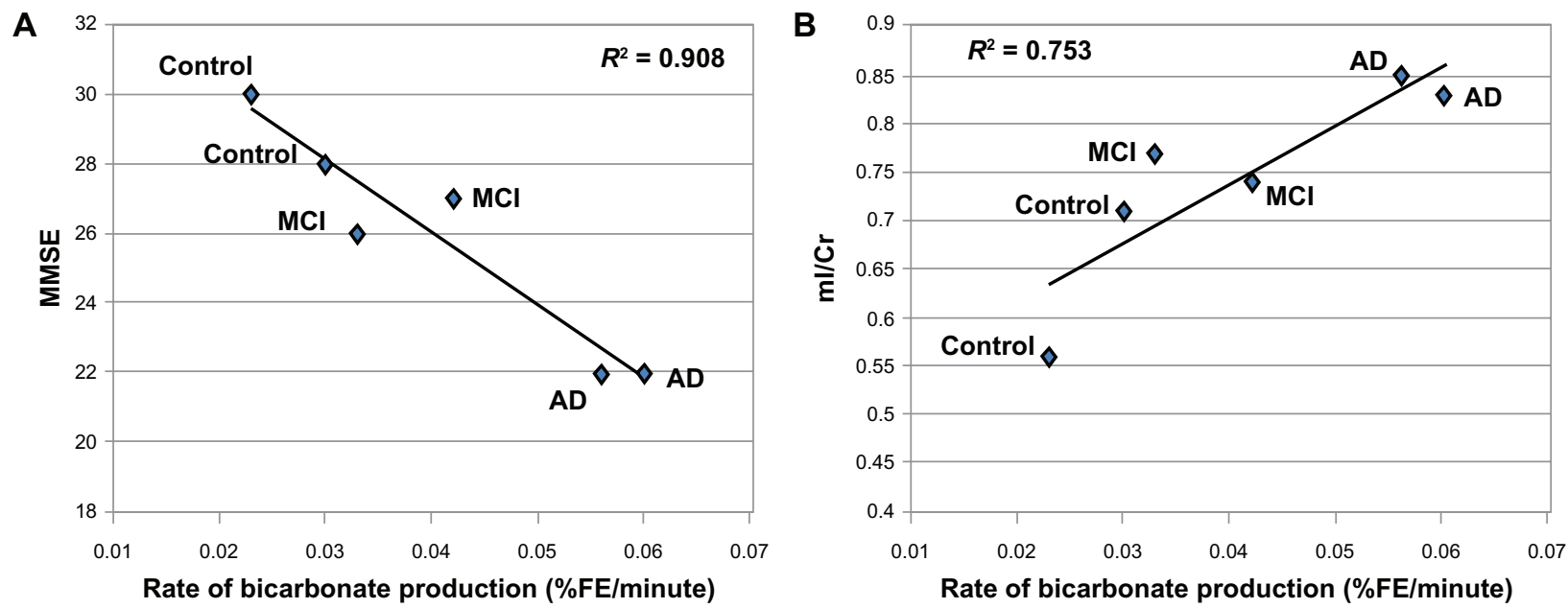

Figure 3 Significant correlation of the rate of bicarbonate productions in \% fractional enrichment (FE) of bicarbonate per minute and the clinical measure, mini-mental state examination (MMSE) with $R^{2}=0.908(\mathbf{A})$ and glial cell density from proton MRS ( $\mathrm{ml} / \mathrm{Cr}$ ) with $R^{2}=0.753(\mathbf{B})$.

Abbreviations: AD, Alzheimer's disease; $\mathrm{Cr}$, creatine; $\mathrm{FE}$, fractional enrichment; ml, myo-inositol; $\mathrm{MCl}$, mild cognitive impairment; $\mathrm{MRS}$, magnetic resonance spectroscopy; MMSE, mini-mental state examination.

similar to results previously reported. ${ }^{5}$ Typical proton MRS spectra in cognitively normal, MCI, and AD subjects are shown in Figure 1.

Glial metabolism of ${ }^{13} \mathrm{C}$ acetate was demonstrated by increased ${ }^{13} \mathrm{C}$ enrichment of cerebral bicarbonate $\left(\mathrm{HCO}_{3}\right.$, $161 \mathrm{ppm}$ ) compared with pre-infusion (Figure 2). The unenriched total creatine resonance ( $\mathrm{tCr}, 158 \mathrm{ppm}$ ) was also observed.

Clinically defined normal, MCI, and AD patients (MMSE normal $=28-30, \mathrm{MCI}=23-27, \mathrm{AD}<23)$ was accompanied by reduction in NAA $/ \mathrm{mI}(-36 \% \pm 0.05 ; P=0.01)$ as previously described. ${ }^{5}$

In contrast, ${ }^{13} \mathrm{C}$ MRS showed a progressive increase in enrichment of the glial-oxidation product, ${ }^{13} \mathrm{C}$-bicarbonate (Figure 2). The increase in glial metabolic activity showed that \%fractional enrichment of bicarbonate was inversely correlated with clinical grade (MMSE) $\left(R^{2}=0.908\right)$ (Figure 3A) and MRS-glial biomarker $(\mathrm{mI} / \mathrm{Cr})\left(R^{2}=0.753\right)$ (Figure $3 \mathrm{~B}$ ). Weak or no correlation was observed for neuronal biomarker (NAA/Cr) and glial metabolic activity $\left(R^{2}=0.11\right)$ (not shown).

\section{Conclusions}

Our preliminary results directly demonstrate progressively elevated glial metabolic rate in patients with $\mathrm{MCI}$ and $\mathrm{AD}$ in proportion to the elevation in glial marker myoinositol of conventional proton MRS, and inversely correlated with a clinical measure of cognitive decline, MMSE. Although the number of patients in this preliminary study is small, the data could contribute to the ongoing debate supporting the general belief that activation of glia observed in animal models, may occur in human MCI and AD.
Neuroscientists have made extensive use of the term 'neuroinflammation' to describe a complex process that occurs when glia cells undergo activation in response to stimuli such as viral infection, ${ }^{25,26}$ undesirable substances, ${ }^{27,28}$ injury, ${ }^{29}$ and illnesses. ${ }^{30}$ Activated microglia and glia cells have been reported in $\mathrm{AD} ., 31,32$ It is possible that our observation of an increase in glial activation is synonymous with neuroinflammation. Additional studies are required to confirm that relationship. If confirmed, ${ }^{13} \mathrm{C}$ MRS after infusion of $1-{ }^{13} \mathrm{C}$ acetate as employed here would provide a practical approach to defining neuroinflammation in human brain. Extending the present observation to larger numbers of well-defined patients and in longitudinal studies which document the onset of glial hyperactivity in comparison with the earliest evidence of neuronal loss (proton MRS or ${ }^{13} \mathrm{C}$ MRS using $1-{ }^{13} \mathrm{C}$ glucose as exogenous substrate are valid techniques ${ }^{33}$ ) could provide direct information on whether neuroinflammation is the immediate cause of $\mathrm{MCI}$ and $\mathrm{AD}$ or merely a secondary effect of neuronal injury. A conclusion in favor of the former mechanism would support the renewed impetus for preventative therapies, which target neuroinflammation in the increasing numbers of patients diagnosed with early AD. Human use of ${ }^{13} \mathrm{C}$ MRS, as demonstrated here, is a safe, nonradioactive technique which can be performed on conventional clinical MRI scanners with only minor modification, and would be a valuable tool for such future studies.

\section{Acknowledgment}

The authors thank Norman Chien, MD for referral of AD subjects, Dr Michael Harrington, Ms Sherri Lee, and the Fuller Seminary students for their assistance in preliminary 
subject screening $(\mathrm{N}=3)$ and $\mathrm{Mr}$ Thomas Warren for his assistance in the infusion protocol. The study is funded by NIDA (K25DA21112, NS) and L.K. Whittier Foundation (BDR, KH, and TT).

\section{Disclosure}

The authors declare no conflicts of interest in this work.

\section{References}

1. Kim S, Swaminathan S, Shen L, et al. Genome-wide association study of CSF biomarkers Abeta1-42, t-tau, and p-tau181p in the ADNI cohort. Neurology. 2011;76(1):69-79.

2. Shaw LM, Vanderstichele H, Knapik-Czajka M, et al. Qualification of the analytical and clinical performance of CSF biomarker analyses in ADNI. Acta Neuropathol. 2011;121(5):597-609.

3. Krause DL, Muller N. Neuroinflammation, microglia and implications for anti-inflammatory treatment in Alzheimer's disease. Int J Alzheimers Dis. 2010;2010:732806.

4. Jack CR Jr, Knopman DS, Jagust WJ, et al. Hypothetical model of dynamic biomarkers of the Alzheimer's pathological cascade. Lancet Neurol. 2010;9(1):119-128.

5. Godbolt AK, Waldman AD, MacManus DG, et al. MRS shows abnormalities before symptoms in familial Alzheimer disease. Neurology. 2006;66(5):718-722.

6. Ross BD, Bluml S, Cowan R, Danielsen E, Farrow N, Gruetter R. In vivo magnetic resonance spectroscopy of human brain: the biophysical basis of dementia. Biophys Chem. 1997;68(1-3):161-172.

7. Ross BD, Danielsen ER, Bluml S. Proton magnetic resonance spectroscopy: the new gold standard for diagnosis of clinical and subclinical hepatic encephalopathy? Dig Dis. 1996;14(Suppl 1):30-39.

8. Ross B, Tran T, Bhattacharya P, Watterson DM, Sailasuta N. Application of NMR spectroscopy in medicinal chemistry and drug discovery. Curr Top Med Chem. 2011;11(1):93-114.

9. Ross B, Lin A, Harris K, Bhattacharya P, Schweinsburg B. Clinical experience with 13C MRS in vivo. NMR Biomed. 2003;16(6-7) 358-369.

10. Lebon V, Petersen KF, Cline GW, et al. Astroglial contribution to brain energy metabolism in humans revealed by $13 \mathrm{C}$ nuclear magnetic resonance spectroscopy: elucidation of the dominant pathway for neurotransmitter glutamate repletion and measurement of astrocytic oxidative metabolism. J Neurosci. 2002;22(5):1523-1531.

11. Rothman DL, Behar KL, Hyder F, Shulman RG. In vivo NMR studies of the glutamate neurotransmitter flux and neuroenergetics: implications for brain function. Annu Rev Physiol. 2003;65:401-427.

12. Bluml S, Moreno A, Hwang JH, Ross BD. 1-(13)C glucose magnetic resonance spectroscopy of pediatric and adult brain disorders. NMR Biomed. 2001;14(1):19-32.

13. Bluml S, Moreno-Torres A, Shic F, Nguy CH, Ross BD. Tricarboxylic acid cycle of glia in the in vivo human brain. NMR Biomed. 2002;15(1):1-5.

14. Sailasuta N, Abulseoud O, Harris KC, Ross BD. Glial dysfunction in abstinent methamphetamine abusers. $J$ Cereb Blood Flow Metab. 2010;30(5):950-960.
15. Van den Berg CJ, Krzalic L, Mela P, Waelsch H. Compartmentation of glutamate metabolism in brain. Evidence for the existence of two different tricarboxylic acid cycles in brain. Biochem J. 1969;113(2): 281-290.

16. Wyss MT, Magistretti PJ, Buck A, Weber B. Labeled acetate as a marker of astrocytic metabolism. J Cereb Blood Flow Metab. 2011 June 8. [Epub ahead of print.]

17. Muir D, Berl S, Clarke DD. Acetate and fluoroacetate as possible markers for glial metabolism in vivo. Brain Res. 1986;380(2):336-340.

18. Boumezbeur F, Mason GF, de Graaf RA, et al. Altered brain mitochondrial metabolism in healthy aging as assessed by in vivo magnetic resonance spectroscopy. J Cereb Blood Flow Metab. 2010;30(1):211-221.

19. Sailasuta N, Tran TT, Harris KC, Ross BD. Swift Acetate Glial Assay (SAGA): an accelerated human (1)(3)C MRS brain exam for clinical diagnostic use. J Magn Reson. 2010;207(2):352-355.

20. Strauss EH, Sherman EMS, Spreen O. A compendium of neuropsychological tests. 3rd ed. New York: Oxford University Press; 2006.

21. Petersen RC. Mild cognitive impairment as a diagnostic entity. $J$ Intern Med. 2004;256(3):183-194.

22. Sailasuta N, Robertson LW, Harris KC, Gropman AL, Allen PS, Ross BD. Clinical NOE 13C MRS for neuropsychiatric disorders of the frontal lobe. J Magn Reson. 2008;195(2):219-225.

23. Sailasuta N, Abulseoud O, Hernandez M, Haghani P, Ross BD. Metabolic abnormalities in abstinent methamphetamine dependent subjects. Subst Abuse. 2010;2010(4):9-20.

24. Provencher SW. Estimation of metabolite concentrations from localized in vivo proton NMR spectra. Magn Reson Med. 1993;30(6): 672-679.

25. Eden A, Price RW, Spudich S, Fuchs D, Hagberg L, Gisslen M. Immune activation of the central nervous system is still present after $>4$ years of effective highly active antiretroviral therapy. $J$ Infect Dis. 2007;196(12):1779-1783.

26. Von Giesen HJ, Wittsack HJ, Wenserski F, Koller H, Hefter H, Arendt G. Basal ganglia metabolite abnormalities in minor motor disorders associated with human immunodeficiency virus type 1. Arch Neurol. 2001;58(8):1281-1286.

27. Sekine Y, Ouchi Y, Sugihara G, et al. Methamphetamine causes microglial activation in the brains of human abusers. J Neurosci. 2008;28(22): 5756-5761.

28. Miguel-Hidalgo JJ. The role of glial cells in drug abuse. Curr Drug Abuse Rev. 2009;2(1):72-82.

29. Hilton GD, Stoica BA, Byrnes KR, Faden AI. Roscovitine reduces neuronal loss, glial activation, and neurologic deficits after brain trauma. J Cereb Blood Flow Metab. 2008;28(11):1845-1859.

30. Graber DJ, Hickey WF, Harris BT. Progressive changes in microglia and macrophages in spinal cord and peripheral nerve in the transgenic rat model of amyotrophic lateral sclerosis. $J$ Neuroinflammation. 2010;7:8.

31. Eikelenboom P, Bate C, Van Gool WA, et al. Neuroinflammation in Alzheimer's disease and prion disease. Glia. 2002;40(2):232-239.

32. McGeer EG, McGeer PL. Inflammatory processes in Alzheimer's disease. Prog Neuropsychopharmacol Biol Psychiatry. 2003;27(5): 741-749.

33. Lin AP, Shic F, Enriquez C, Ross BD. Reduced glutamate neurotransmission in patients with Alzheimer's disease - an in vivo (13)C magnetic resonance spectroscopy study. MAGMA. 2003;16(1):29-42.
Neuropsychiatric Disease and Treatment

\section{Publish your work in this journal}

Neuropsychiatric Disease and Treatment is an international, peerreviewed journal of clinical therapeutics and pharmacology focusing on concise rapid reporting of clinical or pre-clinical studies on a range of neuropsychiatric and neurological disorders. This journal is indexed on PubMed Central, the 'PsycINFO' database and CAS, and is the official

\section{Dovepress}

journal of The International Neuropsychiatric Association (INA). The manuscript management system is completely online and includes a very quick and fair peer-review system, which is all easy to use. Visit http://www.dovepress.com/testimonials.php to read real quotes from published authors. 